\title{
Correction: Skin and Wound Map From 23,453 Nursing Home Resident Records: Relative Prevalence Study
}

\author{
Yunghan $\mathrm{Au}^{1}, \mathrm{PhD}, \mathrm{MBA}$; Marcon Laforet ${ }^{1}, \mathrm{BSc}, \mathrm{MSc}$; Kirsten Talbot ${ }^{1}$; Sheila C Wang ${ }^{2}$, MD, PhD
}

${ }^{1}$ Swift Medical, Toronto, ON, Canada

${ }^{2}$ Division of Dermatology, Department of Medicine, McGill University, Montreal, QC, Canada

\section{Corresponding Author:}

Sheila C Wang, MD, PhD

Division of Dermatology

Department of Medicine

McGill University

Montreal General Hospital

Montreal, QC, H3G 1A4

Canada

Phone: 15149341934

Fax: 15149348520

Email: sheila.wang@mail.mcgill.ca

\section{Related Article:}

Correction of: https://derma.jmir.org/2018/2/e11875

(JMIR Dermatol 2018;1(2):e12495) doi: 10.2196/12495

In "Skin and Wound Map From 23,453 Nursing Home Resident Records: Relative Prevalence Study" (JMIR Dermatol 2018;1(2):e11875) by Au et al, the acronym "CMO" in the Conflicts of Interest section was incorrectly expanded to "chief marketing officer". This has been changed to "chief medical officer" to accurately reflect Sheila C Wang's relationship with Swift Medical.
Additionally, the authors have advised that the degrees for Yunghan Au should be changed from "MBA, $\mathrm{PhD}$ " to "PhD, MBA".

The correction will appear in the online version of the paper on the JMIR website on October 17, 2018, together with the publication of this correction notice.

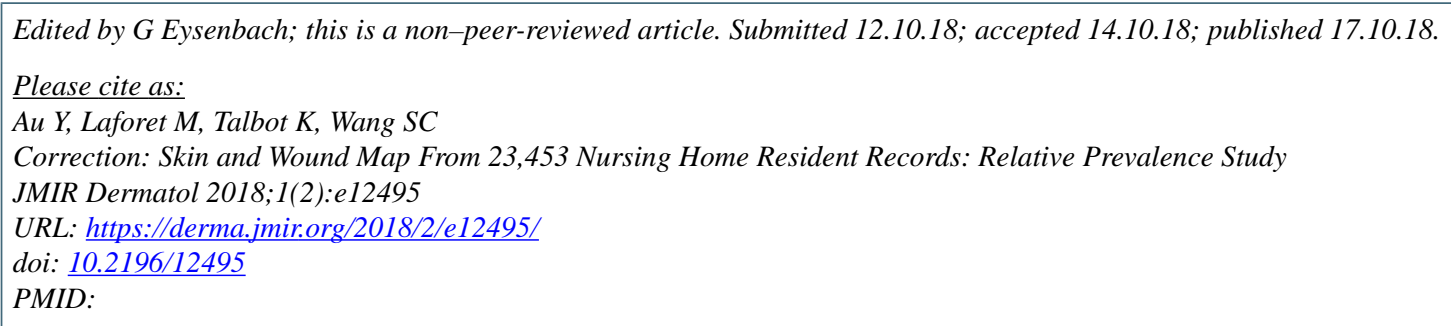

(C) Yunghan Au, Marcon Laforet, Kirsten Talbot, Sheila C Wang. Originally published in JMIR Dermatology (http://derma.jmir.org), 17.10.2018. This is an open-access article distributed under the terms of the Creative Commons Attribution License (https://creativecommons.org/licenses/by/4.0/), which permits unrestricted use, distribution, and reproduction in any medium, provided the original work, first published in JMIR Dermatology Research, is properly cited. The complete bibliographic information, a link to the original publication on http://derma.jmir.org, as well as this copyright and license information must be included. 